УДК 663.14. 033, 663.143.2

\title{
ИССЛЕДОВАНИЕ АБСОРБЦИИ КИСЛОРОДА ВОЗДУХА В ФЕРМЕНТАЦИОННОМ АППАРАТЕ С ДИСКРЕТНО-ИМПУЛЬСНЫМ ВВОДОМ ЭНЕРГИИ
}

\author{
Ободович А.Н., Д.т.н., Фищенко А.Н., к.т.н., Сидоренко В.В.
}

Институт технической теплофизики НАН Украины, ул. Желябова, 2а, Киев, 03680, Украина

У статті представлені результати досліджень 3 впливу обробки поживних середовищ для вирощування дріжджів сахароміцетів методом дискретно-імпульсного введення енергії на швидкість розчинення в них кисню.

Библ. 4, рис. 5.

\begin{abstract}
В статье представлены результаты исследований по влиянию обработки питательных сред для выращивания дрожжей сахаромицетов методом дискретно-импульсного ввода энергии на скорость растворения в них кислорода.
\end{abstract}

The article presents the results of studies on the effect of treatment of nutrient media for growing yeast Saccharomyces cerevisiae by method of discrete-pulse energy input at the rate of dissolved oxygen.

Ключевые слова: дрожжерастильный процесс, растворенный кислород, дискретно-импульсный ввод энергии.

Многие микроорганизмы, используемые в промышленности, для роста нуждаются в молекулярном кислороде, который в процессе аэробного дыхания окисляет субстраты до двуокиси углерода и воды [1]. Кроме того, кислород может включаться в процессы конструктивного метаболизма клеток, обеспечивая синтез ими некоторых соединений.

Растворимость кислорода в культуральной среде незначительна и составляет всего несколько граммов кислорода на $\mathrm{m}^{3}$ [2].

Потребность же аэробных микроорганизмов в кислороде может составлять, десятки килограмм кислорода на $\mathrm{M}^{3}$ культуральной среды в час. Для обеспечения нормальной жизнедеятельности клеток аэрация среды должна быть непрерывной. Прекращение подачи кислорода даже на 15...20 мин резко понижает скорость роста дрожжей, так как ферментные системы клетки перестраиваются с дыхания на брожение. Съем дрожжей с аппарата снижается, так как переориентирование ферментных систем на синтез биомассы требует много времени [3]. Необходимость постоянного поддержания в среде концентрации растворенного кислорода, при которой не лимитируется аэробный процесс, определяет выбор конструкции и характеристики (главным образом, массообменные) ферментера для каждого конкретного процесса.
С целью интесификации процесса культивирования микроорганизмов был создан тепломассообменный аппарат (ферментационная установка с дискретно-импульсным вводом энергии), основным рабочим органом которого является роторно-пульсационный аппарат (РПА), в котором реализуется метод ДИВЭ (рис. 1).

Установка работает следующим образом. В приемный бункер 1 подается мелассное сусло, водный раствор питательных солей и кислот и засевные дрожжи. Затем включают роторнопульсационный аппарат 2, открывают заслонку 3 и 3-хходовой кран 4, который находится в положении, при котором культуральная среда циркулирует через трубопровод рециркуляции 5 по контуру приёмный бункер - роторно-пульсационный аппарат - приёмный бункер.

Во время рециркуляции смеси открывают 2-х ходовой кран, через который, через бактериологический фильтр поступает воздух из атмосферы, за счёт разряжения, создаваемого в приёмном патрубке роторно-пульсационного аппарата. Таким образом смесь культуральной среды и дрожжей насыщается воздухом, который находится в газообразном состоянии. Полученная смесь направляется в рабочую камеру роторно-пульсационного аппарата, где подвергается обработке методом дискретно-импульсного ввода энергии. 


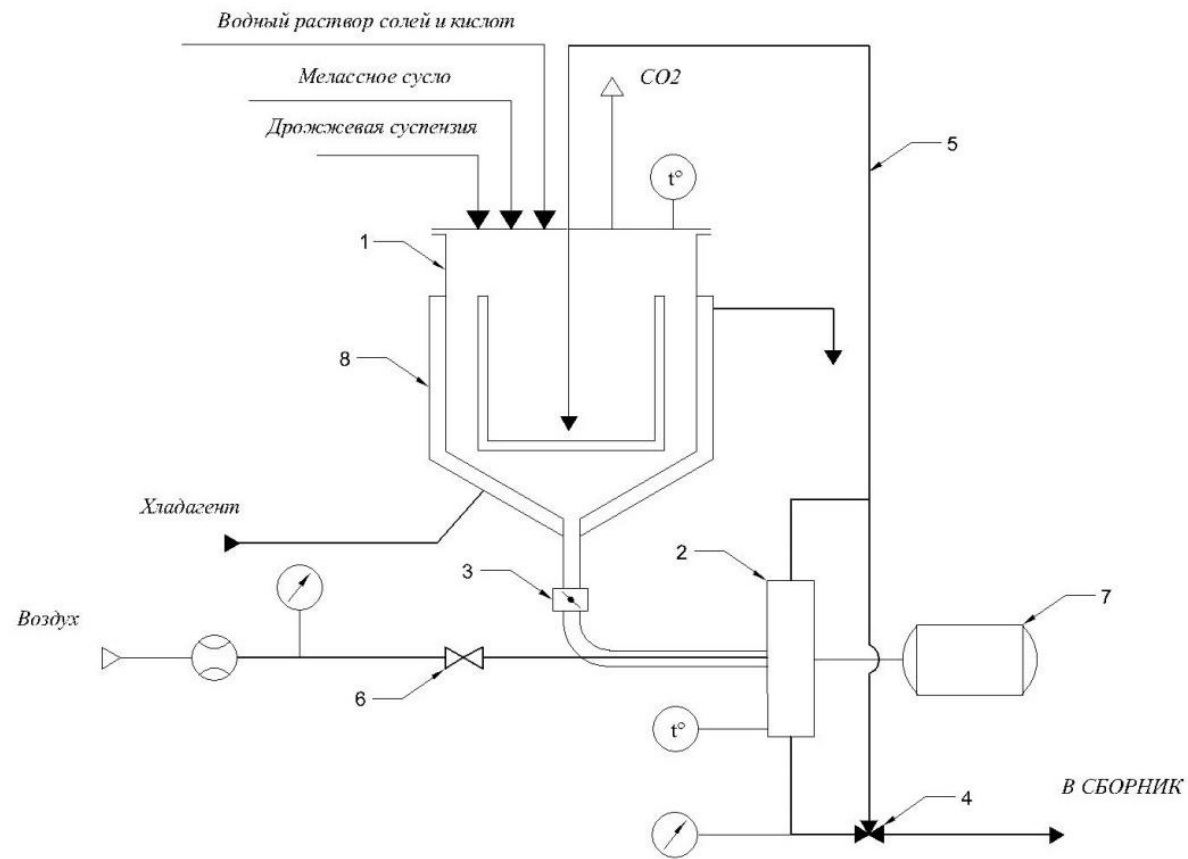

Рис. 1 Аппаратурно - технологическая схема тепломассообменной установки для культивирования микроорганизмов (на примере культивирования хлебопекарских дрожжей).

1 -бункер; 2 -роторно-пульсационный аппарат; 3 -заслонка; 4 - трёхходовой кран; 5 - трубопровод рециркуляции; 6 - двухходовой кран; 7 - двигатель; 8-рубашка охлаждения.

При попадании в полость рабочих органов РПА происходит диспергирование смеси пузырьков воздуха в культуральной среде. Вышедшие из рабочей области пузырьки воздуха имеют наноразмеры, что значительно увеличивает поверхность контакта фаз. Кроме того, смесь воздуха и культуральной среды, проходя через РПА, подвергается воздействию высокочастотных пульсаций давления, сильной турбулизации, разрыву сплошности потока, сдвиговых напряжений и т.д.

Роторно-пульсационный аппарат состоит из корпуса с входным и выходным патрубками, системы трубопроводов для рециркуляции или вывода готовой продукции, горизонтального роторно-пульсационного узла, состоящего из двух роторов и одного статора, размещающихся в одном неподвижном стакане. Вращение роторнопульсационного узла осуществляется с помощью электродвигателя 7. На цилиндрических поверхностях статора и роторов выполнено по 60 сквозных продольных прорезей. Радиальный зазор между рабочими органами ротор - статор - ротор составляет $150 \ldots 300$ мкм. Во время вращения ротора с частотой $1000 \ldots 5000$ мин $^{-1}$ по очереди происходит совмещение пазов статора и роторов, что вызывает значительные перепады давления, высокоградиентных течений в зазорах, а также высоких градиентов сдвиговых напряжений. Локальные скорости сдвига потока могут изменяться от $100 \cdot 10^{2}$ до $100 \cdot 10^{3} \mathrm{c}^{-1}$, частоты импульсов от 0,1 до 10 кГц. В целях отвода тепла, образующегося вследствие диссипации энергии в рабочей зоне РПА и окисления углеродосодержащих соединения дрожжами, в установке предусмотрена охлаждающая рубашка 8.

Управляя механизмами ДИВЭ и меняя конструктивные особенности РПА можно влиять на процессы массопереноса и абсорбции кислорода воздуха в среде.

Учитывая вышесказанное целью работы было изучение влияния механизмов ДИВЭ на процессы абсорбции и массопереноса кислорода в питательных средах с различной концентрацией сухих веществ.

Исследования проводили на питательных средах, применяемых для выращивания дрожжей Saccharomyces cerevisiae, используемых в бродильном и хлебопекарском производстве. 
Исследуемые питательные среды представляют собой водный раствор мелассы с добавлением солей - источников азота, фосфора, магния и калия, подкисленные до рН 5.0. Содержание сухих веществ в этих средах колеблется от десятых долей процента до $10 \%$ [4].

При проведении исследований необходимо было определить зависимость количества растворенного кислорода в воде и питательных средах с различным содержанием сухих веществ от следующих факторов: скорости подачи воздуха, угловой скорости вращения роторного узла, частоты пульсаций потока, скорости сдвига потока, зазора между статором и роторами, количества циклов обработки.

На первом этапе исследований была изучена зависимость концентрации растворённого в воде кислорода от количества циклов обработки при угловой скорости роторно-пульсационного узла от 38,2 до 52,52 об/мин, представленная на рис. 2. Подача воздуха была постоянной и составляла 0,02 л/л·сек. Концентрация растворённого кислорода осуществлялось йодометрическим методом (Винклера).

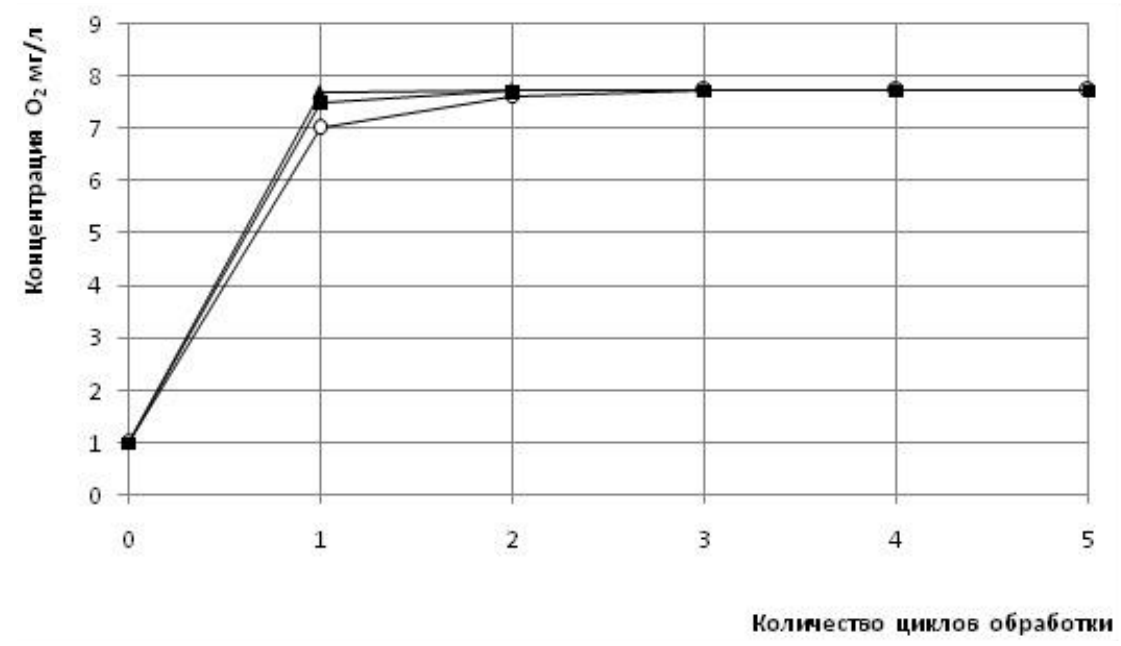

Рис. 2. Зависимость концентрации растворённого кислорода от количества цииклов обработки при угловой скорости вращения роторов: $\Delta-52,52$ об/c; - -47,75 об/c; ○ - 38,2 об/с (кол-во прорезей - 60, зазор - 150 мкм).

Установлено, что с увеличением скорости вращения роторов от 38,2 до 52,52 об/с количество циклов до насыщения воды кислородом (7,74 мг/л) снижается в три раза. Для достижения максимальной концентрации при обработке среды со скоростью вращения роторов 52,52 об/с необходим один цикл, т.е. один проход среды через аппарат, а со скоростью 38,2 об/с - 3 цикла.

Таким образом, можно сделать вывод о том, что с увеличением угловой скорости вращения роторно-пульсационного узла от 38,2 до 52,52 об/мин достичь необходимой концентрации растворённого в воде кислорода можно за меньшее количество циклов, т.е. с меньшей продолжительностью обработки.

При выращивании дрожжей Saccharomyces cerevisiae используется питательная среда с содержанием сухих веществ до 10 \%. Поэтому, следующим этапом исследований было определение концентрации растворённого кислорода в вышеуказанных средах в зависимости от количества циклов обработки, при скорости вращения ротора 47,75 об/с. Объём обрабатываемой жидкости составлял 60 л, период одного цикла 22 сек.

Данные экспериментов представлены на рис. 3.

Анализируя кривые рис. 3 приходим к выводу, что с увеличением концентрации сухих веществ в питательной среде растворимость кислорода уменьшается. Однако, ввиду того, что равновесная концентрация растворённого кислорода в растворах мелассы значительно ниже, чем в воде, для достижения этих значений среду достаточно обрабатывать по 2 цикла. 
При реализации метода ДИВЭ в РПА одним из основных показателей, влияющих на массоперенос, является частота пульсаций потока. Поэтому в дальнейших исследованиях была изучена зависимость концентрации растворён- ного в среде кислорода от частоты пульсаций потока. При проведении эксперимента частоту пульсаций меняли от 2 до 2,865 кГц. Концентрация СВ составляла 10 \% . Результаты исследований представлены на рис. 4.

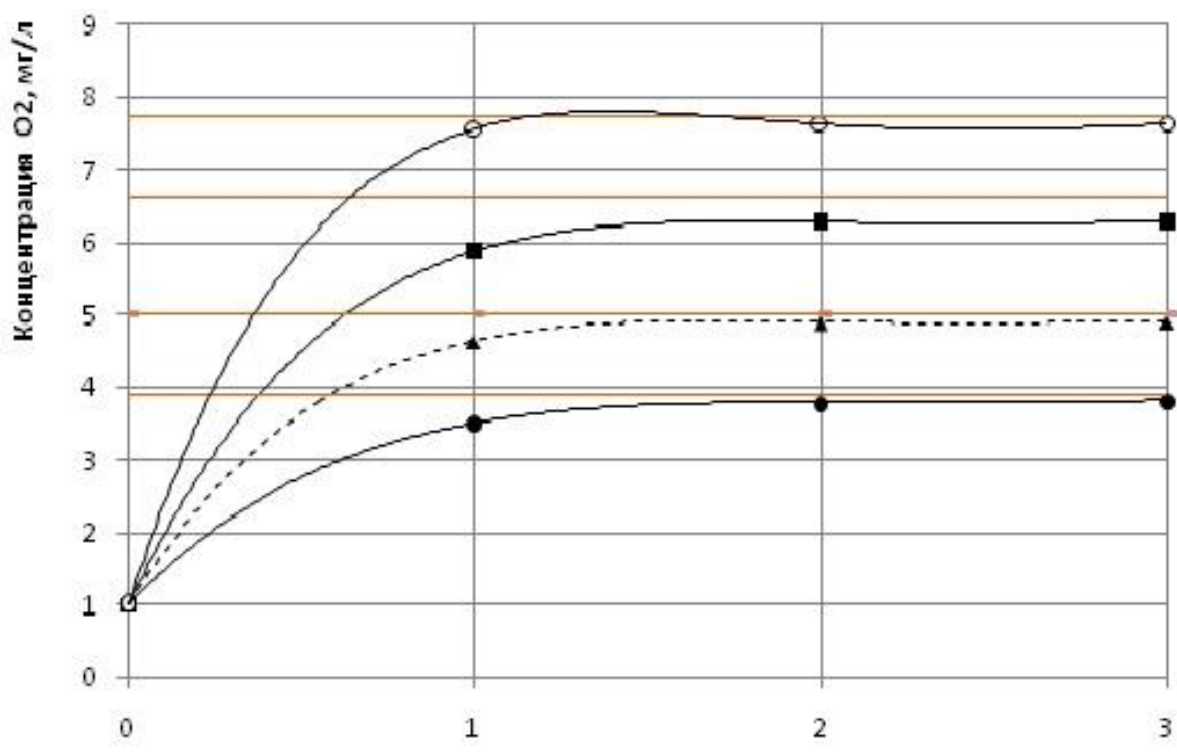

Количество циклов обработии

Рис. З. Зависимость концентрации растворённого кислорода от количества циклов обработки при различной концентрации СВ:

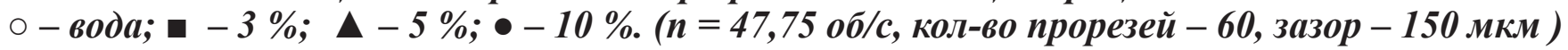

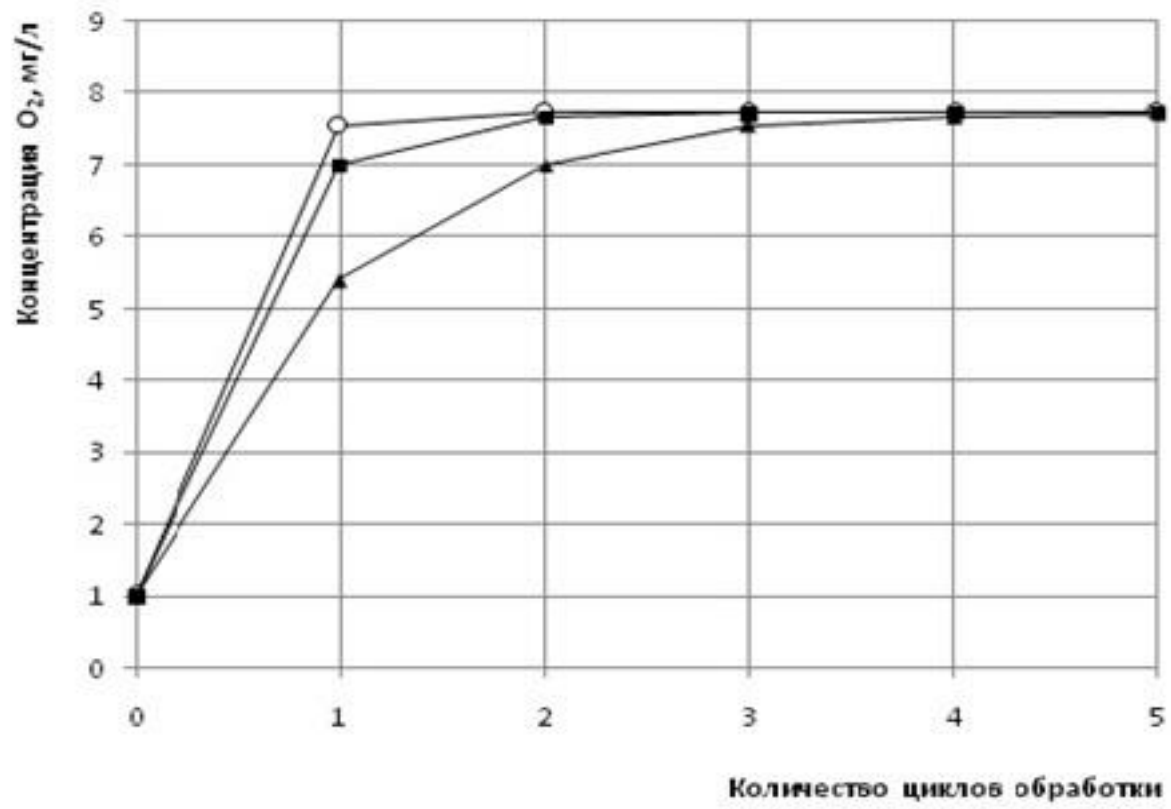

Рис. 4. Зависимость концентрации кислорода от количества циклов обработки при различных частотах пульсаций:

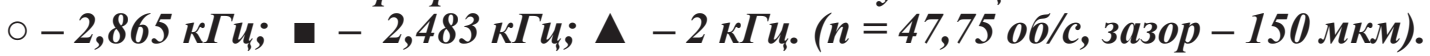


Из результатов исследований видно, что увеличение частоты пульсаций потока среды в РПА позволяет интенсифицировать процесс растворения кислорода. Равновесная концентрация кислорода при обработке среды с частотой пульсаций 2,86 кГц достигается за 2 цикла, при 2,483 кГц - за 3 цикла, при 2 кГц - за 5 циклов. Полученные результаты свидетельствуют о том, что увеличение частоты пульсаций среды в РПА позволяет создать развитую поверхность контакта между газовой и жидкой фазами, что благотворно влияет на массоперенос, позво- ляя сократить продолжительность растворения кислорода [рис. 4].

Взаимосвязь между скоростью потока среды в радиальном направлении РПА и зазора между статором и роторами объединяет величина скорость сдвига потока.

По нашему мнению она также может оказывать влияние на процесс растворения кислорода в питательной среде. На рис. 5 показана зависимость концентрации растворённого в среде кислорода от скорости сдвига потока при концентрации СВ 10 \% и угловой скорости $47,75 \mathrm{c}^{-1}$.

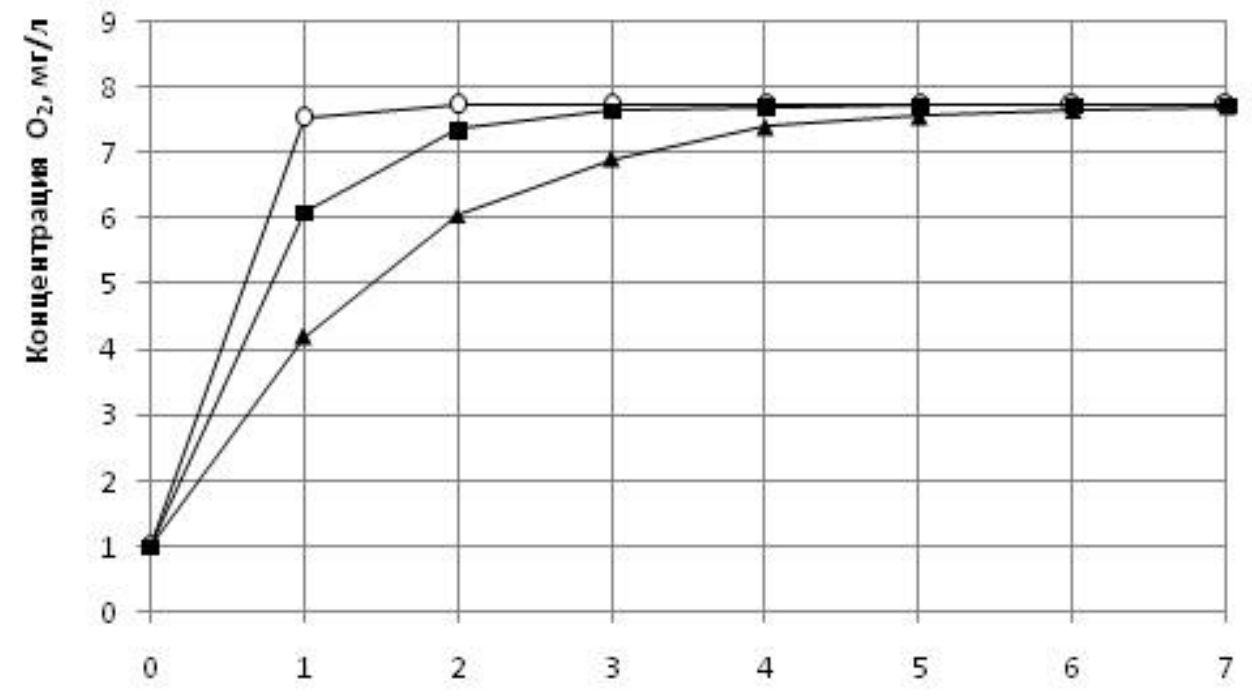

Количество циклов обработки

Рис. 5. Зависимость концентрации растворённого кислорода от количества циклов обработки при различных скоростях сдвига потока:

○- $114 \times 103 c^{-1} ; \square-85,5 \times 103 c^{-1} ; \Delta-57 \times 103 c^{-1}(n=47,75$ об/c, кол-во прорезей - 60).

Результаты исследований подтверждают то, что изменение скорости сдвига потока от $57 \times 10^{3} \mathrm{c}^{-1}$ до $114 \times 10^{3} \mathrm{c}^{-1}$ позволяет сократить количество циклов обработки среды для достижения равновесной концентрации с семи до двух [рис. 5].

Увеличение скорости сдвига потока более $114 \times 10^{3} \mathrm{c}^{-1}$ технически довольно сложно, так как это связано с увеличением угловых скоростей и уменьшением зазора между статором и роторами менее 100 мкм.

Проведенные исследования по растворимости кислорода в воде и питательных средах с различной концентрацией СВ в ферментёре с
ДИВЭ позволяет сделать следующие выводы.

- Ферментёр с применением метода ДИВЭ, который осуществляется посредством РПА целесообразно использовать для насыщения питательных сред кислородом.

- Управляя механизмами ДИВЭ и изменяя конструктивные особенности РПА можно влиять на растворимость кислорода в воде и в питательных средах.

- Увеличение угловых скоростей вращения роторов, частоты пульсаций потока и скорости сдвига потока приводит к интенсификации растворения кислорода. 


\section{ЛИТЕРАТУРА}

1. Промышленная микробиология: Учеб. Пособие для вузов по спец. "Микробиология" и "Биология"/ 3.А. Аркадьева, А.М. Безбородов, И.Н. Блохина и др.; под ред. Н.С. Егорова. - М.: Высшая школа, 1989. - 688 с.

2. Унифицированные методы анализа вод / под ред. Ю.Ю. Лурье. - 2-е изд., исправленное.
- М.: Химия, 1973. - 376 с.

3. Производство хлебопекарных дрожжей/ Н.М.Семихатова, М.Ф. Лозенко, Л.Д. Белова, А.Д. Дмитриев, С.П. Папок - 2-е издание, перераб. и доп. - М.: ВО “Агропромиздат”, 1987. - c. 272

4. Бекер M.Е. Введение в биотехнологию / M.Е. Бекер. - М.: Пищевая промышленность, 1978. - c. 232

\section{RESEARCH OF AIR OXIGEN ABSORBTION IN THE FERMENTATION APPARATUS WITH DISCRETE-PULSE INPUT OF ENERGY}

\section{A. Obodovich , A. Fischenko, V. Sidorenko}

Institute of Engineering Thermophysics, National Academy of Sciences of Ukraine, Zhelyabova str., 2a, Kiev, 03680, Ukraine

The article presents the results of studies on the effect of treatment of nutrient media for growing yeast Saccharomyces method of discrete-pulse input energy at the rate of dissolved oxygen. General provisions on the effect of environment on the aeration process of the growth of yeast are covered. The scheme of the fermentation installation and the order of its work is present. The data on the dependence of the rate of dissolved oxygen in the water and nutrient media on the parameters of their treatment in a rotor-pulsation apparatus.

Key words: the process of growing the yeast, dissolved oxygen, discrete-pulse energy input.

References 4, figures 5.

1. Industrial microbiology / [Z.A. Arkadeva, A.M. Bezborodov, I.N. Blohina at al.]; by edition N.S. Egorov. - M.: Vyisshaya shkola, 1989. - 688 p. (Rus)

2. Standardized methods of analysis of waters / by ed. Y.Y. Lure. - 2d ed. - M.: Himiya1973. - 376 p. (Rus)

3. Production ofbaker's yeast/ N.M.Semihatova, M.F. Lozenko, L.D. Belova, A.D. Dmitriev, S.P. Papok - 2d ed. M.: VO "Agropromizdat", 1987. 272p. (Rus)

4. Beker M.E. Introduction to Biotechnology/ V.T. Beker - M.: Pishchevaya promyshlennost, 1978. - 232 p. (Rus) 